\title{
LA PALABRA ACONTECIMIENTO: CLARICE LISPECTOR EN SUS \\ CRÓNICAS DE JORNAL DO BRASIL (1967-1973)
}

\author{
María Guillermina Feudal ${ }^{*}$
}

\section{RESUMEN}

La convocatoria a escribir en el Jornal do Brasil implicó un desafío a la palabra literaria de Clarice Lispector. Sin embargo, atravesar el umbral y transgredir las fronteras genéricas supuso, en sus crónicas, la conservación del misterio y de su palabra como acontecimiento.

Palabras clave: crónica - desafío - palabra literaria - género

\section{THE WORD-EVENT: CLARICE LISPECTOR IN HER CHRONICLES OF JORNAL DO BRASIL (1967-1973)}

\begin{abstract}
The invitation to write in the Jornal do Brasil meant a challenge to Clarice Lispector's literary word. However, in her chronicles she found a way to preserve the mystery and her word as an event, by transcending genre boundaries.
\end{abstract}

Keywords: chronicle - challenge - literay word - genre

Licenciada y profesora en Letras por la Universidad de Buenos Aires (UBA). Actualmente cursa la maestría en Literaturas española y latinoamericana (UBA) y trabaja como docente-investigadora en la Universidad de General Sarmiento (UNGS), Buenos Aires. E-mail: guillerminafeudal@gmail.com 


\section{Narrador y misterio}

Vamos a decir la verdad: esto de aquí no es para nada una crónica. Esto tan sólo es. No entra en un género. Los géneros ya no me interesan. Lo que me interesa es el misterio" ${ }^{\prime}$

En la década del sesenta Barthes (1968) y Foucault (1969) - en una línea de indagación deudora de los análisis freudianos de lo inconsciente, de la consideración del signo como ideológico y de la teoría saussuriana del lenguaje - adhirieron a la idea de la muerte del autor, es decir, a la imposibilidad de atribuirle a un sujeto biográfico la intencionalidad de lo escrito.

Con unas décadas de anticipación, Benjamin había percibido y anotado en su artículo "El narrador", de 1936, que la capacidad de articular la experiencia en palabras estaba en retroceso. El progresivo avance de las formas narrativas dependientes de la palabra impresa, como la novela, y los abruptos cambios tecnológicos llegados con la primera guerra mundial habían privado paulatinamente a los hombres de los relatos y consejos que se transmiten de boca en boca y circulan entre ellos como una forma de legado. Sin embargo, una de las amenazas más certeras que Benjamin diagnosticó contra esta forma específica de la comunicación fue el surgimiento de la prensa. La información, con su plétora de explicaciones plausibles de hechos recientes - una forma del verosímil legitimado como instrumento del capitalismo que aspira a devorarse lo real - se opone a los silencios de la narración, a las elipsis constitutivas de todo relato que hacen lugar a la conjetura sin fin sobre lo inexplicado y lo inexplicable del mundo. Para Benjamin, el arte de narrar consiste en referir una historia con la mayor precisión, de modo que lo extraordinario o lo prodigioso abran las puertas de la sorpresa y la reflexión. La información, por el contrario, nace y vive en el instante, y su autoridad se la concede la explicitación de una causalidad, que por su naturaleza está destinada a sofocar el piso resbaladizo de la incertidumbre y a agotar la proliferación de sentidos. Además, para asimilar el misterio hace falta permanecer "olvidado de sí mismo" y atento a la escucha de una narración teñida de las circunstancias en las que le fue referida al narrador. ${ }^{2}$

\footnotetext{
${ }^{1}$ LISPECTOR, Clarice. "Máquina escribiendo" In Revelación de un mundo. Buenos Aires: Adriana Hidalgo Editora, 2008, p. 264.

${ }^{2}$ BENJAMIN, 1999, p. 118.
} 
El narrador, en este sentido, puede verse como la figura en la que confluyen los relatos de las experiencias de vida (del pasado reciente, de la lejanía, de los mil focos de la cultura, diría Barthes) que recibe de otros narradores, y que contribuye a acrecentar con las suyas. Al conservar las huellas de quien habla, en lugar de girar en el vacío, la narración se anuda en la vida del comunicante, y de este modo lo narrado se va nutriendo de las finísimas capas de múltiples versiones e inscribiéndose en el curso de la historia.

Al observar que la prensa pone en crisis la narración, Benjamin tiene que reconocer que la figura del narrador entra en crisis con ella. $\mathrm{Y}$ ese progresivo desvanecimiento deja pues un lugar que es ocupado por la explicación ${ }^{3}$ que, con su función esclarecedora, se hace cargo de ponerle fin al misterio o, en otras palabras, de continuar con el avance del desencantamiento del mundo que se inicia con la modernidad a fines del siglo XIX.

Pero en un movimiento que se niega a atribuirle la muerte del narrador "a una manifestación de decadencia" o, lo que es lo mismo, a la "modernidad", al establecer con optimismo que la caída de la narración hace sentir una nueva belleza en lo que se desvanece, Benjamin habilita también a pensar en una belleza de lo nuevo.

¿Cómo sería posible, entonces, pensar a Clarice Lispector en su función de cronista del Jornal do Brasil?

Cuando llega al diario, ella es la típica novelista desasistida de consejo de la que habla Benjamin. No obstante, es capaz de llevar adelante una práctica semejante a la del narrador de Benjamin, la de la conservación del misterio. Ella elige otear el horizonte desde una playa y tragarse el agua salada para sentir que es posible conocer el mar, consustanciarse con él. ${ }^{4}$ Como dice Antelo (2002), es una vigía del mundo: "No

\footnotetext{
${ }^{3}$ Recordemos que la pregunta inicial de Barthes (1987) en su texto "La muerte del autor" es quién habla en el espacio de escritura que se abre con su muerte. Foucault (1998) constata, en su artículo "Qué es un autor", que ya no importa quién habla sino las diversas funciones de autor que aparecen cuando ya no es posible vincular lo escrito con el nombre propio de un sujeto biográfico, es decir, con su intencionalidad. En paralelo a la pretensión de registrar la realidad día a día que adviene con la circulación de la información periodística y otros avances tecnológicos propios de la modernidad, como la fotografía y el cine, la crítica literaria y filosófica no pueden ya aceptar el vínculo directo presupuesto entre la palabra y su referente.

${ }^{4}$ El cuento "Ritual", publicado en las crónicas como reescritura de un evento de la infancia en el texto "Baños de mar" (también en las crónicas), tiene como protagonista a la mujer adulta que continúa el ritual de purificación adentrándose a las aguas frías del mar durante la madrugada. Luego de contemplar el horizonte y meterse paulatinamente en el agua, ella hace un cuenco con las manos y se traga el agua salada: "Y era eso lo que le faltaba: el mar por dentro como el líquido espeso de un hombre. Ahora ella está toda igual a sí misma" (LISPECTOR, 2008, p. 100). Lo que resalta aquí el narrador es la simbólica consustanciación que se produce entre la naturaleza y el hombre, el valor del encuentro entre dos mundos
} 
sabe nada. No ha leído a los filósofos. Y sin embargo juraríamos oírlos susurrar entre sus bosques. Lo descubre todo." ${ }^{5}$ El enigma se esconde entre las cosas del mundo, y el juego de máscaras detrás de las que se oculta cuando teclea en su máquina le permite ensayar múltiples caminos de acceso hacia lo que no es. Foucault (1998), en su artículo “¿Qué es un autor?”, analiza la manera en que la muerte del autor hizo aparecer los múltiples egos que en un mismo discurso ejercen distintas y hasta contradictorias funciones. Para eso los usa Lispector. Pero a fuerza de negarse permanentemente como escritora y como lectora. Desestimando la cultura del statu quo y su afán clasificatorio es que puede encarnarse involuntariamente en alternativos egos.

Para Lispector esto siempre ha sido así, hasta el punto de molestarse por el hecho de ser convocada a dar conferencias como integrante de la institución de la literatura brasileña. Dice que eso la hace sentirse, más que parte del hecho literario, reclutada. Quizá, una designación como ésta le impediría esconderse y fragmentarse detrás de las máscaras; quebraría su relación con el acto de la escritura al que se somete impulsivamente y que surge, como lo inconsciente, de forma involuntaria y para su propia sorpresa.

En su elección de la palabra como dominio sobre el mundo, el escribir mismo es tomado por ella como un acontecimiento al que sólo la escritura en acto le es inherente:

\footnotetext{
Porque realmente, ¿cómo se escribe? ¿qué se dice? ¿cómo se dice? Y ¿cómo se empieza? Y ¿qué se hace con el papel en blanco que nos enfrenta tranquilo? Sé que la respuesta, por más que intrigue, es esta única: escribiendo. Soy la persona que más se sorprende al escribir. Y todavía no me habitué a que me llamen escritora [...] Sólo me consideraré escritora el día en que yo diga: sé cómo se escribe"
}

Clarice Lispector elige, entonces, permanecer olvidada de sí misma cuando escribe. Prefiere ser hablada por las múltiples capas del lenguaje del mundo a ser devorada por su nombre propio. Su práctica está rodeada de un aura que quiere conservar para su propio bien. En un punto de partida como este, su escritura no podría ser explicada sin ser absorbida - devorada por - una teoría que la tuviera como objeto

inconmensurables y además inaprehensibles mediante el uso de la razón: "Podría haber un encuentro de sus misterios sólo si uno se entregase al otro: la entrega de dos mundos incognoscibles hecha con la confianza con la que se entregarían dos comprensiones" (LISPECTOR, 2008, p. 99).

${ }^{5}$ Cf. ANTELO, 2002, p. 9 - 29

${ }^{6}$ LISPECTOR, 2008, p. 136. 
de estudio y cancelara con ello lo extraordinario que se esconde en el impulso. El escribir, en el mundo clariceano, es la motivación inexplicada de la escritura.

La posición de Lispector ante la escritura y la palabra condensa pues lo más sustancial del narrador de Benjamin: conservación del misterio; olvido de sí mismo; palabra anudada a la vida - experiencia - del comunicante; pero también hace suya la divisa que signa la escritura moderna, para la que "escribir ya no puede seguir designando una operación de registro, de constatación". 7

Sin embargo, la convocatoria en 1967 a escribir en Jornal do Brasil la acercó peligrosamente a la zona de crisis anunciada por Benjamin. Rodeada de "información", Lispector vio el peligro de no poder distraerse y caer en la palabra herramienta, la palabra "transparente" más allá de la cual se yergue un referente único para todos. Irónicamente, la aceptación de esta propuesta la llevó a explicarse, porque tuvo que admitir que necesitaba dinero. Explicándose, entonces, halló la forma de escapar al martirio. Sin máscaras ahora tras las que metamorfosear sus múltiples egos expuso el artesanado de la práctica de escribir y aceptó, resignada, estampar su firma al pie de cada columna. A lo largo de sus crónicas reunidas es posible ver la insistencia con la que la escritora - escurridiza y misteriosa pero devenida ahora cronista popular - se aboca a analizar el acto de escritura: puede tanto decir que escribir es bello y revelador como que es imposible o que hubiera preferido callar. Como si en cada insistencia estuviera a punto de revelarse una verdad, o como si urgida a quitarse las máscaras y a reconocer que es ella quien habla finalmente pudiera encontrarse con su yo. El acto mismo de escribir se convierte en un tema recurrente puesto en la vitrina, a la vista de todos esos lectores de diarios hacia los que condesciende, hacia los que baja para explicarles cómo es que no es posible saber cómo se escribe y que muchas veces la palabra - cuando se trata del significado comúnmente aceptado - es un estorbo para acceder al mundo. No obstante, circulando en el diario, ante la mirada de un público vasto y anónimo, sus palabras llegaron a más lectores y allí gritó y demostró tanto como pudo que la palabra inmotivada no es más que eso, una palabra sin motivo, sin conexión con lo real, sin explicación: un lujo que quien está olvidado de sí mismo puede darse, como ella, para transformarla en acontecimiento.

\section{Palabra y dinero}

\footnotetext{
${ }^{7}$ BARTHES, 1987, p. 68.
} 
Desde 1967 hasta 1973 el Jornal do Brasil publicó, todos los sábados, pequeños textos de Clarice Lispector. ¿Crónicas, notas, reflexiones sobre la vida cotidiana, relatos de ficción? Reconocida en el ámbito de las letras brasileñas como novelista y cuentista (su primera novela, Cerca del corazón salvaje, se publica en 1944), Lispector aceptó volver a la prensa porque, como declara en el mismo espacio del diario, necesitaba el dinero:

Todavía me siento un poco perdida en mi nueva función con eso que no puede llamarse propiamente una crónica. Y, además de ser neófita en el asunto, también lo soy en materia de escribir para ganar dinero. Ya trabajé en prensa como profesional, sin firmar. Al firmar, sin embargo, me vuelvo automáticamente más personal. Y siento un poco como si estuviera vendiendo mi alma. ${ }^{9}$

El dinero, entonces, entra en la escritura de Lispector como una motivación que pone en riesgo su escritura y la obliga a desnudarse.

El pacto con el diario - que demanda su nombre propio como garantía de valor - y su necesidad de dinero le exigen explicar, para explicarse a sí misma, en qué devienen la palabra y sus múltiples egos cuando están condicionados por un factor que obedece a la lógica del intercambio. Porque la firma la remite a su nombre propio y la palabra, que en sus manos es un lujo, podría corromperse. Sería más correcto decir que la escritura incondicionada es para ella un acto gratuito que "si tiene causas, éstas son desconocidas. Y si tiene consecuencias, son imprevisibles"10. Dicho por ella como reformulación del concepto de escritura inmotivada, es claro que para Lispector escribir es una práctica ponderada para penetrar en el mundo y explorarlo, porque como se ocupa de insistir, el milagro de la comprensión es difícil de encontrar y, de producirse, dura muy poco. El lenguaje es, en este sentido, el aquí y ahora de la palabra, irreductible a la cosa. Válido y necesario en el momento de la indagación, el único fondo contra el cual contrastarlo sería la oscuridad temible de una verdad que enceguece: "Pero tengo

\footnotetext{
${ }^{8}$ LISPECTOR, Clarice. "Fragmentos" In Revelación de un mundo. Buenos Aires: Adriana Hidalgo,2008, p. 289.

${ }_{9}^{9}$ LISPECTOR, 2008, p. 16

${ }^{10}$ Idem p. 307.
} 
miedo: escribir mucho y siempre puede corromper la palabra. Sería más protector vender o fabricar zapatos: la palabra quedaría intacta. Lástima que no sé hacer zapatos". 11

La acidez empleada aquí como valoración de la palabra que entrega no solamente implica el gasto de la frecuencia del uso; en el hecho de firmar, de poner su nombre propio como garantía, la palabra se le desplaza hacia su yo personal, a la vida privada que quiere preservar, y en ese proceso se le escurre la intimidad, la vende: "Les vendo, pues, a ustedes, con el mayor placer, una cierta parte de mi alma - la parte para la charla del sábado"12. Habría que pensar, entonces, que lo que está en juego en esta transacción es la distancia benéfica la ficción. En la ficción no hay verdaderos ni falsos, tampoco contradicciones, solo caminos de indagación de lo real. Y el proceso de escritura periodística, por el contrario, es correlativo de un uso referencial del lenguaje, muy lejos de la ambición de Lispector, para quien la palabra no sólo no es transparente sino que traba la intuición, a cuyo servicio se la acepta: "Mis intuiciones se vuelven más claras con el esfuerzo de trasladarlas a las palabras. Esto escribí cierta vez. Pero está equivocado, pues, al escribir, pegoteada y pegada, va la intuición. Es peligroso porque nunca se sabe qué ocurrirá - si se es sincero". ${ }^{13}$

En el pasaje de la literatura al diario, las variables tiempo y dinero convierten la palabra un bien equivalente a un par de zapatos y al escritor en un productor semejante a un zapatero. Usando la terminología de Andrade (1998), la palabra pasa a ser irónicamente canibalizada por los mecanismos de consumo de una sociedad burguesa que la fetichiza ${ }^{14}$. En este camino, la palabra perdería el valor de culto añorado por Lispector. En el uso periodístico transitaría el camino hacia la palabraherramienta para expresar lo que está afuera del lenguaje, y lo que se desvirtúa en ese trayecto no es el referente sino la palabra como acontecimiento.

En este sentido, el espacio abierto por publicación de una columna semanal en el diario (la realidad cotidiana, "lo real" por antonomasia) es aprovechado por Lispector para poner en escena mecanismos por medio de los cuales transitar la canibalización y convertir la crónica en un puente que devele la incongruencia entre la palabra objeto y la palabra herramienta y hacer de ella su tema.

\footnotetext{
${ }^{11}$ Idem p. 313.

${ }^{12}$ Idem p. 16.

${ }^{13}$ Idem p. 150.

${ }^{14}$ ANDRADE, 1998, p. 155.
} 
Así como en el cuento "La mujer más pequeña del mundo"15 la pigmea negra y embarazada, bautizada "Pequeña Flor", codicia las botas y el anillo del científico y desbarata con su risa al representante de la cultura occidental colonizadora, Clarice Lispector convierte la crónica literalmente en una vitrina. En ese espacio sui generis, creado de la nada por ella, mezcla arbitrariamente los objetos: las voces narrativas, los temas, las formas, la evaluación de lo narrado y la evaluación del procedimiento. Cuentos, aforismos, reflexiones sobre la vida cotidiana, gritos de desesperación y desencanto, agradecimiento infinito a la grandeza de la creación aparecen sucesivamente a lo largo de los siete años de escritura en el diario. ${ }^{16}$ Como en la vida misma, parece decir Lispector, en la que no hay jerarquías predeterminadas, lo bello se relativiza con lo feo; lo bueno con lo malo; lo alto con lo bajo. O bien, como en la vida moderna, la proliferación de objetos llega al punto de hacerlos a todos equivalentes, consumibles, porque están allí, en la vitrina para ser tomados en su calidad de objetos intercambiables.

Es el gesto estético de crear una dialéctica entre lo sublime y la desublimación, al decir de Moriconi (2000), lo que prevalece en la última etapa de la escritura de Lispector. Clarice Lispector se devora el espacio que le ofrece el diario, se muestra más carente que nunca - necesita el dinero - y lo devora todo: todos los temas pueden ser suyos; todas las voces pueden tener su lugar. La divisa de comerse el mundo parece orientarla cuando escribe ahora, porque tiene una carencia muy grande.

No obstante, la incertidumbre misma de la clasificación, explicitada en ese desorden, llega a constituirse en el aquí y ahora de una palabra singularmente clariceana. En una mezcla sin explicación, la reunión de fragmentos sólo se hace posible en la figura de la cronista Lispector, ni cronista medieval ni narradora, tan sólo una cronista moderna.

\section{El género en la vitrina}

\footnotetext{
${ }^{15}$ LISPECTOR, Clarice. "La mujer más pequeña del mundo" In Cuentos reunidos. Madrid: Siruela, 2008.

${ }^{16}$ Con la publicación en Jornal do Brasil de cuentos enteros como "Tortura y gloria" o "Miedo a la eternidad", fragmentos de cuentos como "Ritual" - que se publica en libro con el nombre de "Las aguas del mundo"-, o bien cuentos largos que fracciona en ediciones sucesivas aprovechando las virtudes del folletín, Lispector pone en evidencia su escaso interés por las fronteras genéricas y sus soportes y, por el contrario, demuestra el potencial que se genera en sus cruces y superposiciones. Ella se opone a todos los ritos de la clasificación, pues paralizan la circulación del sentido, tanto como le teme a la tiranía de la eternidad, lo estático por antonomasia.
} 
Ensanchar los límites de los géneros, cruzarlos, reescribirlos es una de las estrategias que Lispector lleva al diario para mostrar qué puede haber detrás de toda construcción social.

"Crónica social" es uno de los textos de Revelación de un mundo que parece adecuarse desde el título al objeto del género: relato cronológico de un hecho social relevante. Se trata de un almuerzo entre señoras de la alta burguesía brasileña, pero es el almuerzo mismo, un repertorio de mozos mudos, flores y elegancia el que en realidad se las devora a ellas. Entretanto, las señoras bellas, perfectamente correctas y elegantes, hacen tanto esfuerzo por estar a la altura del acontecimiento que son incapaces de "ver" o de "sentir" que están siendo devoradas por lo que ellas creen poseer. Sabemos que esto es así porque la voz del narrador teje paralelamente el desencanto: simplemente hace visibles los andamios sobre los que se estructura el mandato social naturalizado:

\begin{abstract}
Si bien todas tenían derecho a ese ambiente, parecían no obstante recelar del momento de meter la pata. Ése es el momento en que cierta realidad se revela. El almuerzo estaba bien servido, por completo alejado de cualquier rastro de cocina: antes de la llegada de las invitadas se habían ocultado todos los andamios. ${ }^{17}$
\end{abstract}

En este texto, entonces, a la descripción prototípica de la crónica se le imprime la voz oculta de las invitadas, lo que ellas verdaderamente sienten o piensan pero que reprimen en sus posturas fingidas, en el acartonamiento de las pautas sociales de la cortesía. "No", dice la cronista para terminar, el almuerzo no fue perfecto, añadiendo de este modo al género su propia voz.

En la "crónica" del 3 de abril de 1971, titulada "De natura florum", Lispector escribe sobre las flores. Para ello elige un acápite del libro II del Génesis y redacta a continuación su propio diccionario de flores escogidas. En la entrada de "Siempreviva", por ejemplo, dice: "Es una siempremuerta. Su sequedad tiende a la eternidad. Su nombre en griego quiere decir sol de oro" ${ }^{" 18}$. Es fácil advertir cómo recurre a su propia "génesis" del sentido y nada menos que al género diccionario, ámbito de la preservación de los significados aceptados y legitimados por la cultura, para reescribirlo. En este caso, imprime sobre un género discursivo canónico su propia visión / percepción del

${ }^{17}$ Op. cit, LISPECTOR, 2008, p. 152
${ }^{18}$ Idem p. 259. 
mundo. Por otro lado, también cuestiona metafóricamente la fosilización de los significados al definir a la llamada "siempreviva" como la "siempremuerta".

Este mismo procedimiento de revelar los andamios ocultos detrás de toda construcción social (el foco de atención aquí es probablemente uno de los tantos almuerzos a los que ella asistió como escritora pero también como esposa) es llevado a las crónicas para mostrar en su escritura el andamiaje que la sostiene, "meter la pata" y permitir que "cierta realidad se revele"19. Las observaciones citadas son incluso válidas como valoración de la literatura abocada a la representación realista a la que su retórica se opone por definición. ${ }^{20}$

De todas maneras el objetivo de Lispector no es solamente mostrar que la escritura es intransitiva porque es artificial, sino poner de relieve su posición frente al hecho de escribir. La hora de la basura opera sin duda como la hora del cansancio, en la que la radicalidad de la escritura autorreflexiva elige mostrarse sin velos como acto lujoso, gratuito, irreductible a la voluntad ajena - sea ésta la institución literaria o la institución periodística - e incluso, al dinero. Pero además, cierta actitud de irreverencia frente a la escritura como práctica y como experiencia (como articuladora de experiencia del escribir mismo) la lleva al paroxismo de negar su capacidad para escribir. ¿Se escribe para qué? ¿Se escribe para quién? ¿Cómo se escribe? Estas tres preguntas constituyen el nudo de la escritura clariceana y sus respuestas se van construyendo sobre el principio estructurador de la confrontación entre el saber y el no saber, poder y no poder, querer y no querer escribir.

En este sentido, la fuerte exposición a la que se ve sometida con la demanda periodística parecería fortalecer la necesidad de poner en primer plano sus principios escriturales de modo un modo tan evidente y a la vez contradictorio que se torne imposible otorgarle un sentido último, preciso o, en última instancia, mortífero. La hora

\footnotetext{
${ }^{19}$ Idem p. 152.

${ }^{20} \mathrm{Al}$ respecto, Ítalo Moriconi sostiene que "El diagnóstico del caso Clarice como radical o idiosincrático se explica, en un primer momento, por su inadecuación a la hegemonía de los valores nacionalistas, historicistas y referencialistas hegemónicos en la valoración crítica de la literatura del canon modernista" MORRICONI, 2001, p. 1). Raúl Antelo, por su parte, añade que su literatura tampoco podría ubicarse en como respuesta dialéctica a la tensión entre vanguardismo y regionalismo. Su apuesta pasa por otra cosa. Lispector no escribe con el horizonte de la historia literaria como motor. Como se ha visto, ella elabora su propia metodología para integrar la percepción y la palabra sólo en el instante del acontecimiento, más allá de cual es necesario volver a hacer el esfuerzo de sentir / percibir / escribir / reescribir. En este sentido, la reescritura y la repetición constituyen el intento por captar un instante nuevo aunque la palabra y la sintaxis no puedan ser evitadas. Por eso, puede decir que "la suya es una escritura pautada por un constante diferimiento de la intencionalidad, como si esa fuera la mejor estrategia tendiente a la aparición de la apertura y al evento de la ausencia" (ANTELO, “¿Qué significa Clarice Lispector para la literatura brasileña?” - apunte de cátedra sin año de edición ni página).
} 
de la basura ya no es siquiera la hora del "como sí". Es la hora del "como es". Y más vale no mentir, ni mentirse, so pena de alcanzar el objeto de lujo más buscado por Lispector: el silencio.

“¿Ven ustedes a qué gusto estoy escribiendo? Sin mucho sentido, pero a gusto. ¿Qué importa el sentido? El sentido soy yo". ${ }^{21}$

La escritura como un lujo. El lujo, además de expresar el exceso representa lo innecesario, el gasto puro de lo que no puede explicarse, el arma más temida de ataque a la lógica racionalista y tecnócrata. Se escribe no sólo a gusto sino sin sentido. Por lo demás, estas tres aristas de la escritura: innecesariedad, gratuidad y deriva del sentido sólo le atañen a quien escribe. El lector, si quiere, también puede entrar en la lógica. Pero verá si le sirve.

La estrategia de Lispector se yergue sobre tres pilares que se imbrican: escritura, lenguaje y género. De sus textos se desprende que, para ella, la escritura es un acto en el que adviene la palabra, para acercarse al mundo, como acontecimiento irrepetible. La forma resultante, por lo tanto, no puede ceñirse a formas genéricas predeterminadas, es decir, canónicas. Es en este sentido que los textos de Lispector siempre dan la impresión de ser transgresores cuando, en realidad, opera por detrás una coherencia deliberada. En este procedimiento, podría decirse íntimo, hace su aparición Jornal do Brasil, atravesándolo con una lógica nueva. El diario la convoca por su nombre consagrado, y le paga por ello. A cambio, le confiere libertad temática. Pero ella conserva una ética basada en la sinceridad. Y ausculta por sí misma de qué se trata el género, qué temas le son pertinentes, ¿cómo son los lectores que elegirán leer sus notas cada sábado? Lispector está parada, pues, ante una puerta nueva y elige atravesar el umbral.

\section{La hora de la basura}

Para Ítalo Moriconi (2000), el fragmentarismo de la última etapa de la producción de Lispector, que incluye los libros Agua viva, La hora de la estrella, Un soplo de vida, los cuentos reunidos en El vía crucis del cuerpo y sus textos del Jornal do Brasil, constituye lo que ella misma llamó "la hora de la basura", donde se ponen en

${ }^{21}$ Op. cit., LISPECTOR, 2008, p. 160. 
escena "los límites y la extenuación de un proyecto que de progresiva radicalización de la escritura autorreflexiva.",22

La hora de la basura se fundaría, para Moriconi, en una dualidad entre lo literario y lo periodístico, lo popular y lo meditativo, lo irónico y lo sentimental. Pero si bien es factible constatar esta dualidad en las crónicas, sería más exacto hablar de ellas como una instancia en la que ni lo literario ni lo periodístico se mantienen en la estrechez de sus fronteras genéricas. Se trataría más bien de una instancia transgenérica en la que lo que se vende sigue siendo el lujo de la circulación del sentido, más allá de las prerrogativas académicas, culturales o comerciales. Justamente la hora de la basura trabaja a tal punto la porosidad de y entre los géneros que ni en uno ni en otro es posible rescatar mecanismos narrativos o periodísticos "puros", como la figura de narrador En La hora de la estrella o del cronista tradicional en sus Crónicas.

Como Pequeña Flor, Clarice Lispector también puede ser caníbal. El procedimiento de hacer visible la escena de la escritura y a la vez señalar el límite - la extenuación - es la mostración del imprevisible acto gratuito de escribir, mediante el que incluso está dispuesta a correr el riesgo de que su palabra se encuentre con el lado oscuro de la corrupción. Con ello, la ambivalencia en la que se fundan sus textos pasa a ser la única garantía de la preservación de un misterio que está a punto de zozobrar. Poner en escena el acto de la escritura y su límite tiene la doble función de desacralizar la palabra y mostrar cómo, al intentar captarlo, el misterio se escurre para permanecer intacto. En este sentido, la vía privilegiada para contrarrestar las consecuencias de que la banalidad de lo real - el diario, el dinero - se devore lo aurático del mundo no pasa por la negación o la resistencia sino por avalar la confluencia imprevista de lo heterogéneo y hacerla estallar en una nueva belleza. Es este gesto insolente, controversial, el que da sentido a todos los textos reunidos en las crónicas. Por otro lado, una vía por la cual es posible hacer que un poco de lujo destelle en medio de la basura es hacer de la pérdida una ganancia. Ella, que se resiste a ser devorada o totalizada por el rótulo de escritor y que se ve impelida a descartar su anonimato y

\footnotetext{
${ }^{22}$ Por cierto, el paralelismo entre La hora de la estrella y "la hora de la basura" (MORICONI, 2000, p. 2) está construido con la misma risa sarcástica del narrador luego de haber matado a su personaje Macabea y de Pequeña flor ante su colonizador. La misma risa con la Benjamin declara en "Experiencia y pobreza" que es posible sobrevivir a la cultura. "Tal vez esta risa suene a algo bárbaro. Bien está. Que cada uno ceda a ratos un poco de humanidad a esa masa que un día se la devolverá con intereses, incluso con interés compuesto" (BENJAMIN, 1933, p. 173).
} 
vender el nombre propio sigue viendo en la literatura un resto (un lujo) donde ejercer las dudas, los interrogantes, lo insondable del misterio.

Ya no sé escribir, perdí el don [...] No sé ya escribir y, sin embargo, el hecho literario se volvió de a poco tan sin importancia para mí que no saber escribir tal vez sea exactamente lo que me salvará de la literatura. ¿Qué se volvió importante para mí? Sea lo que fuere será a través de la literatura como podrá tal vez manifestarse. ${ }^{23}$

No se puede escribir sobre Lispector sin contradecirse, porque es ella la que elige poner en escena "los dolorosos maridajes de los contrarios". ${ }^{24}$

${ }^{23}$ Op. cit., LISPECTOR, 2008, p. 92

${ }^{24}$ Op. cit. Cf. ANTELO, 2002, p. 9 - 29. 


\section{REFERÊNCIAS}

ANDRADE, Ana Luiza. Saturno Devorador da Modernidade: Imagens / Sensações. In: Revista Brasileira de Literatura Comparada, ABRALIC/Florianópolis, n. 4, 1998.

ANTELO, Raúl. Qué significa Clarice Lispector para la historia brasileña? [apunte de cátedra. Sin año de edición ni página].

2002 (p. $9-29)$

"Prólogo". In.: LISPECTOR, Clarice. La araña. Buenos Aires: Corregidor,

BARTHES, Roland. La muerte del autor. In: EI susurro del lenguaje. Barcelona:

Paidós, 1987.

BENJAMIN, Walter. El narrador. In: Para una crítica de la violencia y otros ensayos Madrid: Taurus, 1999.

BENJAMIN, Walter. Experiencia y pobreza. In: Discursos interrumpidos Madrid: Taurus, 1994.

FOUCAULT, Michel. ¿Qué es un autor? Revista Litoral, Córdoba, n. 25/26, abr.1998.

LISPECTOR, Clarice. La hora de la estrella. Madrid: Siruela, 2000.

Revelación de un mundo. Buenos Aires: Adriana Hidalgo, 2008.

MORICONI, Ítalo. La hora de la basura. Radarlibros. Suplemento de Página 12. Buenos Aires, mar. 2000. 